\title{
A systematic review and meta-analyses of regional perfusion in donation after circulatory death solid organ transplantation
}

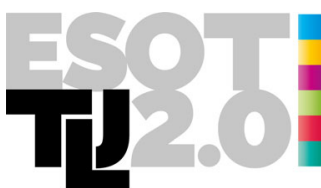

TRANSPLANTATION LEARNING JOURNEY

Julie De Beule $e^{1,+}$ Katrien Vandendriessche $e^{2, \dagger}$ Liset H. M. Pengel ${ }^{3}$ John H. Dark ${ }^{5}$ (D, Amelia J. Hessheimer ${ }^{6}$ (D) Hendrikus J. A. N. Kimenai ${ }^{7}$ Arne P. Neyrinck 9,10 Ina Jochmans ${ }^{1,15}$

1 Transplantation Research Group, Department of Microbiology, Immunology, and Transplantation, KU Leuven, Leuven, Belgium

2 Department of Cardiovascular

Sciences, Cardiac Surgery, KU Leuven, Leuven, Belgium

3 Nuffield Department of Surgical Sciences, Centre for Evidence in

Transplantation, University of Oxford, Oxford, UK

4 Department of Emergency Medicine and Surgery, Azienda Ospedaliera San Camillo Forlanini, Rome, Italy

5 Faculty of Medical Sciences, Translational and Clinical Research Institute, Newcastle University, Newcastle, UK

6 Department of General \& Digestive Surgery, Institut Clínic de Malalties Digestives i Metabòliques (ICMDM), Hospital Clínic, IDIBAPS, CIBERehd, University of Barcelona, Barcelona, Spain 7 Division of Transplant Surgery, Department of Surgery, Erasmus MC University Medical Center, Rotterdam, The Netherlands

8 Nuffield Department of Surgical

Sciences, University of Oxford,

Oxford, UK

9 Department of Cardiovascular Sciences, Anesthesiology and Algology, KU Leuven, Leuven, Belgium

10 Department of Anesthesiology, University Hospitals Leuven, Leuven, Belgium

11 Donation and Transplant Coordination Unit, Hospital Clínic,

\section{SUMMARY}

In donation after circulatory death (DCD), (thoraco)abdominal regional perfusion (RP) restores circulation to a region of the body following death declaration. We systematically reviewed outcomes of solid organ transplantation after RP by searching PubMed, Embase, and Cochrane libraries. Eighty-eight articles reporting on outcomes of liver, kidney, pancreas, heart, and lung transplants or donor/organ utilization were identified. Meta-analyses were conducted when possible. Methodological quality was assessed using National Institutes of Health (NIH)-scoring tools. Case reports (13/88), case series (44/ 88 ), retrospective cohort studies (35/88), retrospective matched cohort studies $(5 / 88)$, and case-control studies (2/88) were identified, with overall fair quality. As blood viscosity and rheology change below $20^{\circ} \mathrm{C}$, studies were grouped as hypothermic $\left(\mathrm{HRP}, \leq 20^{\circ} \mathrm{C}\right)$ or normothermic $\left(\mathrm{NRP},>20{ }^{\circ} \mathrm{C}\right)$ regional perfusion. Data demonstrate that RP is a safe alternative to in situ cold preservation (ISP) in uncontrolled and controlled DCDs. The scarce HRP data are from before 2005. NRP appears to reduce post-transplant complications, especially biliary complications in controlled DCD livers, compared with ISP. Comparisons for kidney and pancreas with ISP are needed but there is no evidence that NRP is detrimental. Additional data on NRP in thoracic organs are needed. Whether RP increases donor or organ utilization needs further research.

\section{Transplant International 2021;}

\section{Key words}

donation after circulatory death, meta-analysis, regional perfusion, solid organ transplantation, systematic review

Received: 2 June 2021; Revision requested: 16 September 2021; Accepted: 20 September 2021

\section{Correspondence}

Ina Jochmans, Abdominal Transplant Surgery, University Hospitals Leuven, Herestraat 49, 3000 Leuven, Belgium.

Tel.: +32 16348727 ;

fax: +32 16348743 ;

e-mail: ina.jochmans@uzleuven.be 
University of Barcelona, Barcelona,

Spain

12 Department of Surgery, Addenbrooke's Hospital, University of Cambridge, Cambridge, UK

13 The NIHR Cambridge Biomedical Research Centre, Cambridge, UK

14 Department of Cardiac Surgery, University Hospitals Leuven, Leuven, Belgium

15 Department of Abdominal Transplant Surgery, University Hospitals Leuven, Leuven, Belgium

${ }^{\dagger}$ These authors contributed equally.

\section{Introduction}

Donation after circulatory death (DCD) expands the deceased donor pool (Fig. S1), but faces two major hurdles linked to detrimental effects of warm ischaemia. Compared with donation after brain death (DBD), more post-transplant complications and lower utilization rates are reported in DCD (Fig. S2) [1-9]. In contrast to rapid recovery after in situ cold preservation (ISP) [10], regional perfusion (RP) in DCD restores circulation following death declaration [11,12]. Perfusion is limited to the abdomen (abdominal-RP, A-RP) or abdomen and chest (thoracoabdominal-RP, TA-RP). RP is thought to improve post-transplant outcomes by minimizing the impact of warm ischaemia, as ATP concentrations are restored, and ischaemic preconditioning mechanisms might be triggered [13-15]. This is important as DCD livers experience higher rates of primary non-function (PNF), early allograft dysfunction (EAD), and biliary complications; DCD kidneys higher rates of PNF and delayed graft function (DGF); and DCD pancreata more thrombosis [6,16-19] compared with DBD though the latter has been contradicted in a recent study from the United Kingdom [20]. DCD lungs offer similar outcomes compared with DBD $[21,22]$. DCD heart transplantation is in its infancy and uses ex situ or in situ organ perfusion [23]. RP is also believed to increase the utilization rates because organ viability can be assessed and recovery is less hurried [24].

In Europe, RP has become the standard or preferred method for DCD donation in at least five countries [1]. In December 2019, the European Society for Organ Transplantation (ESOT) established a Work stream of European experts to create a consensus statement within the Transplantation Learning Journey project (Box 1) [25]. As no randomized controlled trial (RCT) has compared RP with ISP in DCD and different protocols, with temperatures ranging from 4 to $37^{\circ} \mathrm{C}$, have been described, we undertook a systematic review to inform the consensus Worksteam. The systematic review and meta-analyses aimed to summarize the outcomes after transplantation of livers, kidneys, pancreata, hearts, and lungs from RP-DCD donors.

\section{Methods}

\section{Search strategy}

PubMed, Embase, and Cochrane libraries were searched from inception through August 27, 2020 with support of an experienced librarian (search strategies in Appendix S1). Reference lists of included articles were manually searched for additional records. Articles needed to report on in situ perfusion using extracorporeal membrane oxygenation technology, regardless of temperature, in human subjects that were potential deceased organ donors (Appendix S2). Records were screened by at least two independent reviewers, who achieved consensus on included studies. This systematic review, registered with PROSPERO (CRD42019120480), uses MOOSE-guidelines for reporting [26].

\section{Outcome measures}

Primary outcome measures were post-transplant outcomes (early graft function, graft failure, patient survival). Secondary outcome measures assessed utilization by donor conversion rate (DCR; number of a donors divided by number of potential donors) and organ utilization rate (OUR; number of organs transplanted divided by total number of available organs from actual donors). A potential donor was a patient with a devastating brain injury or lesion or circulatory failure and otherwise medically suitable to donate; a utilized donor was a deceased person from whom at least one donated organ had been transplanted [27]. We assumed every donor had two kidneys, and recognizing this might have led to underestimation of the OUR.

\section{Selection of primary study reports, data extraction, management, and quality assessment}

Data set redundancy was assessed and a primary study report was assigned for each study (Appendix S3). Presentation and analysis of primary outcome data only included primary study reports, unless secondary study reports contained different outcomes or comparator groups. 
Box 1. European Society for Organ Transplantation (ESOT) and the Transplantation Learning Journey (TLJ) project Work streams within the TLJ project help to achieve the primary aim of ESOT - to improve patient access to (and outcomes in) transplantation. TLJ Work streams facilitate objective discussion of scientific and clinical research, and expert opinion to ensure that all perspectives on a topic are considered, with clinically relevant end goals in mind.

ESOT seeks to progress transplantation research, practice and education, and to collaborate with other international bodies, to ensure that policies and regulations are globally consistent and relevant, and based on strong scientific, ethical, and clinical foundations.

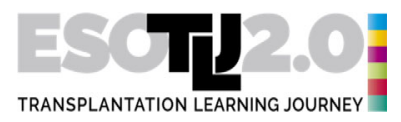

www.esot.org

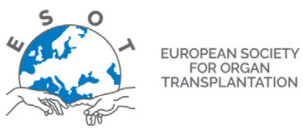

Data variables of interest were pre-defined; for each study group, donor and recipient demographics, posttransplant outcome data, and data needed to calculate DCR and OUR were extracted by four independent reviewers, while a fifth reviewer checked $10 \%$ of data for accuracy. Methodological quality was assessed by two independent reviewers using the National Institutes of Health (NIH) scoring tools for retrospective observational studies [28]. Case reports were not scored for methodological quality.

\section{Data synthesis}

Despite the likelihood that clinical data were heterogeneous, meta-analyses were considered valuable in the absence of Level 1 evidence (Appendix S4). Temperatures $\leq 20{ }^{\circ} \mathrm{C}$ have important implications for rheology and blood viscosity [29,30]. Therefore, RP was categorized as hypothermic (HRP; 0-20 ${ }^{\circ} \mathrm{C}$ ) or normothermic RP (NRP, 21-37.5 ${ }^{\circ} \mathrm{C}$ ). When RP temperature was not mentioned, authors were contacted or temperature was deduced (Appendix S5). Outcomes were grouped by donor type [uncontrolled (uDCD) and controlled DCD ( $\mathrm{cDCD}$ ) [31]], as causes and mechanism of death vary, as do lengths and dynamics of hypoperfusion and hypoxic periods.

Meta-analyses were conducted if at least three studies were available (Cochrane RevMan v.5.4.1). Studies with DCD-ISP would be the relevant comparator group for meta-analyses. However, as these were not always available, studies with a DBD comparator group were also considered. Random-effect models were used to calculate pooled estimates and $95 \%$ confidence intervals (95\% CI) and $I^{2}$-tests assessed statistical heterogeneity. Percentages were recalculated to absolute numbers, and sample means and standard deviations (SD) are presented. The latter were estimated from the sample size, median, range, and/or interquartile range (IQR), when necessary [32]. For time-to-event data, point estimates were determined from Kaplan-Meier graphs, using WebPlotDigitizer v.4.3 (Ankit Rohatgi, CA, USA), unless the necessary data points were reported [33]. We report risk ratios (RR) for categorical data, standardized mean differences (SMD) for continuous data, and hazard ratios (HR) for time-to-event data. All effect estimates were obtained by random-effects analysis and Mantel-Haenzel methods except for continuous and time-to-event data where inverse variance methods were used. Anticipated absolute effects were obtained using GRADEpro (McMaster University and Evidence Prime Inc, Ontario, CA, USA) [34]. GraphPad Prism 9 (San Diego, CA, USA) was used to create summary forest plots.

\section{Results}

\section{Study description and quality assessment}

Among 14,309 records, 88 met inclusion criteria (Fig. 1, Table S1) [35-122]. These studies are summarized in Appendix S6. Articles were case reports $(13 / 88,13 \%)$ or series $(44 / 88,44 \%)$, retrospective cohort studies $(35 / 88$, $35 \%)$, retrospective matched cohort studies $(5 / 88,6 \%)$, and case-control studies $(2 / 88,2 \%)$. Quality was assessed as good (16\%), fair (68\%), or poor $(11 \%)$ (Tables S2-S4). Articles reported on uDCD (39/88, $44 \%)$, cDCD $(43 / 88,49 \%)$, or $\mathrm{u} / \mathrm{cDCD}(6 / 88,7 \%)$. In the latter, both uDCDs and cDCDs were included and reported as one group. Primary study reports were assigned for papers reporting on primary outcome measures (Tables S5-S9). Most studies on A-NRP reported outcomes of a single organ, with only three providing outcomes on all abdominal organs $[83,93,94]$. There were no publications on HRP after 2005 suggesting that this technique might no longer be clinically relevant. 


\section{Regional perfusion in $\mathrm{uDCD}$}

Hypothermic regional perfusion in $u D C D$

Liver: One cohort study described 14 RP uDCD livers, subsequently cold stored [96]. Results are difficult to interpret as seven livers were perfused at $15-20^{\circ} \mathrm{C}$ and 7 at $37^{\circ} \mathrm{C}$ (Tables S10 and S11).

Kidney: Four retrospective cohort studies were identified [36,74,111,117] (Tables S12 and S13). All kidneys were cold stored. Compared with ISP, lower PNF rates after HRP with high DGF rates in both were reported [117]. Compared with DBD, lower PNF rates but higher DGF rates after HRP have been described [36,74]. Oneyear graft survival of HRP was lower versus DBD [111].

Lungs: One study compared lung recovery after ISP with simultaneous A-HRP to DBD [116] (Tables S16 and S17). Lungs were cold stored. Use of perioperative mechanical support and ventilation days were comparable, though primary graft dysfunction (PGD) grades 2 and 3 and bronchial anastomotic complications were more frequent in uDCD. One-year graft and patient survival were comparable.

\section{Normothermic regional perfusion in $u D C D$}

Liver: Seven primary studies were identified [48,56,63,66,92,96,112] (Tables S10 and S11; Fig. 2). Two studies were not considered further as they reported on NRP in $\mathrm{u} / \mathrm{cDCD}$ liver transplantation, where outcomes could not be separated [48,92]. All livers were cold stored. No comparisons of NRP to ISP in uDCD were identified, restricting meta-analyses to comparing $\mathrm{uDCD}-\mathrm{NRP}$ with DBD.

Graft function: High PNF (8-29\%) and EAD rates (31\%, Olthoff criteria [123]) with NRP were reported. PNF was higher after NRP compared with DBD (8\% vs. $1.5 \%)$.

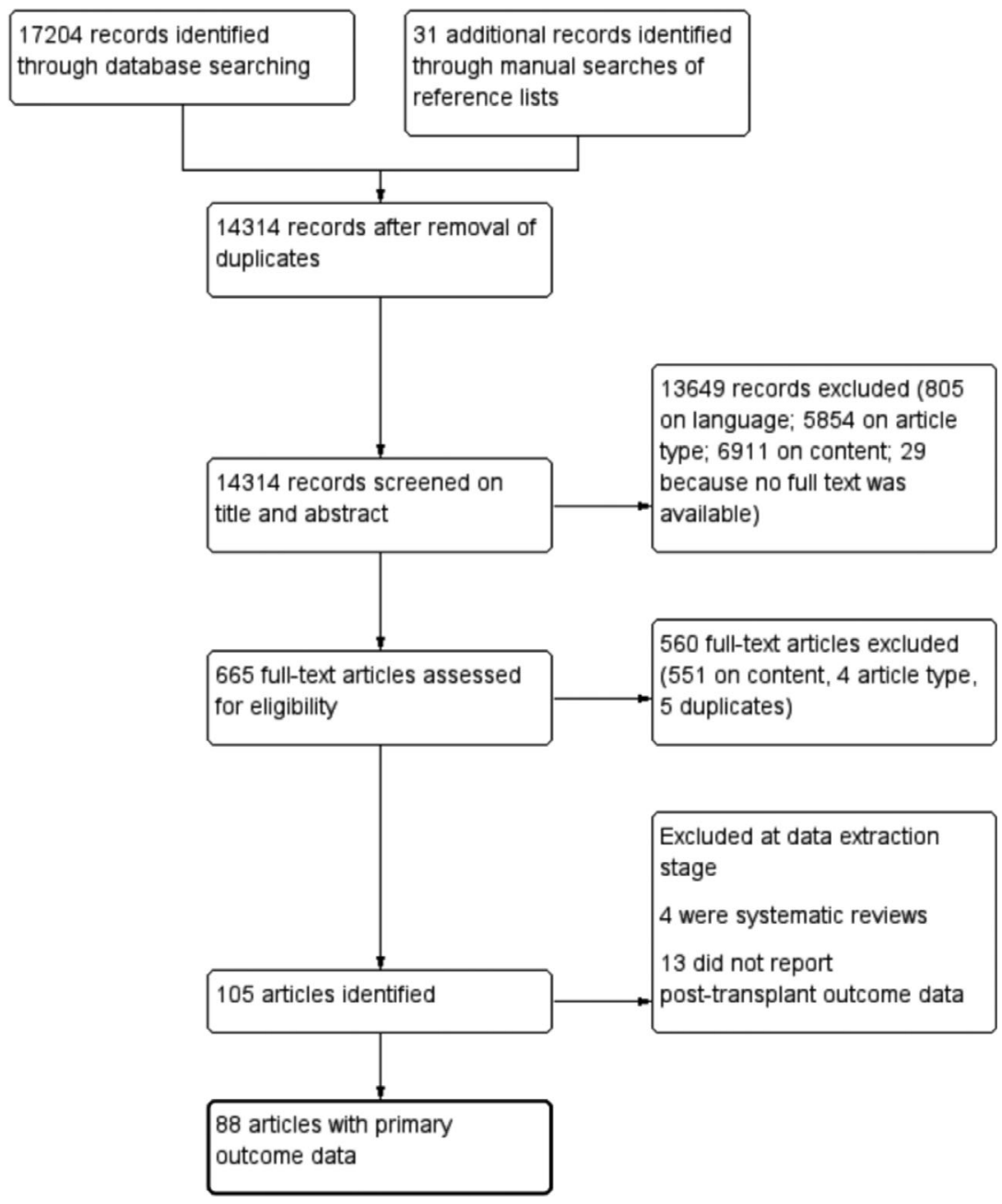

Figure 1 Study flow diagram. 
Biliary complications: Variable rates of ischaemic cholangiopathy (IC) (8-20\%) and anastomotic strictures (3-15\%) were described. More IC and anastomotic biliary strictures were noted after NRP compared with DBD ( $16 \%$ vs. $3 \% ; 6.7 \%$ vs. $1.9 \%$, respectively).

Graft and patient survival: High retransplantation rates $(12-23 \%)$, with 1-year graft survival rates between $69 \%$ and $73 \%$ (different definitions used) were reported. Compared with DBD, NRP uDCD liver transplantation had higher retransplantation rates $(4.5 \%$ vs. $12 \%)$ and lower 1-year graft survival (87\% vs. $73 \%)$ [66]. Meta-analysis showed an increased risk of graft failure after NRP in uDCD compared with DBD (HR 2.64, 95\% CI 1.28-5.48; Figs 2 and S3). One-year patient survival rates appeared lower after NRP compared with DBD (83\% versus $89 \%$, respectively) [66]. Meta-analysis confirmed this finding (HR 2.67, 95\% CI 1.03-6.94; Figs 2 and S3).

Kidney: Ten primary studies were identified [39,50, $60,73,75,98,100,106,109,117$ ] (Tables S12 and S13; Fig. 2). Kidneys were mostly cold stored, though hypothermic machine perfusion (HMP) was described.

Graft function: PNF of $0-11 \%$ was reported. In a French registry analysis, NRP was not independently associated with PNF compared with ISP in uDCD (odds ratio (OR) 1.83, 95\% CI 0.78-4.25) [39]. Spanish national data showed that ISP in uDCD (OR 5.7; 95\%
CI 2.4-13.3) and HRP (OR 4.0; 95\% CI 1.7-9.2) were independently associated with increased PNF risk compared with NRP [50]. However, meta-analysis of available studies did not show a difference in PNF risk between NRP and ISP (RR 0.61, 95\% CI 0.14-2.69; Figs 2 and S4). DGF rates varied widely and were as high as $100 \%$. Compared with NRP, both ISP (OR 2.7; 95\% CI 1.0-7.2) and HRP (OR 1.6; 95\% CI 0.9-2.8) were independently associated with increased risk of DGF [50]. Meta-analysis of available studies did not show a difference in DGF risk between NRP and ISP (RR 0.72, 95\% CI 0.48-1.09; Figs 2 and S3). Compared with DBD, meta-analysis showed 1.6 times higher risk of DGF after NRP (RR 1.59, 95\% CI 1.38-1.83; Figs 2 and S5). Meta-analysis did not show a difference in acute rejection after NRP versus DBD (RR 0.66, 95\% CI 0.35-1.26; Figs 2 and S5). One-year mean creatinine of 1.3 and $1.5 \mathrm{mg} / \mathrm{dl}$ and mean glomerular filtration rate (GFR) between 73 and $76 \mathrm{ml} / \mathrm{min} / 1.73 \mathrm{~m}^{2}$ were reported. Compared with DBD, meta-analysis did not show a difference in 1-year GFR after NRP (SMD 0.29, 95\% CI -0.36 to 0.93 ; Figs 2 and S5), though there was high degree of heterogeneity. Whether HMP influences outcomes has not been studied.

Graft and patient survival: Different graft survival definitions were used, making interpretation difficult. Oneyear graft survival rates varied between $40 \%$ and $90 \%$.

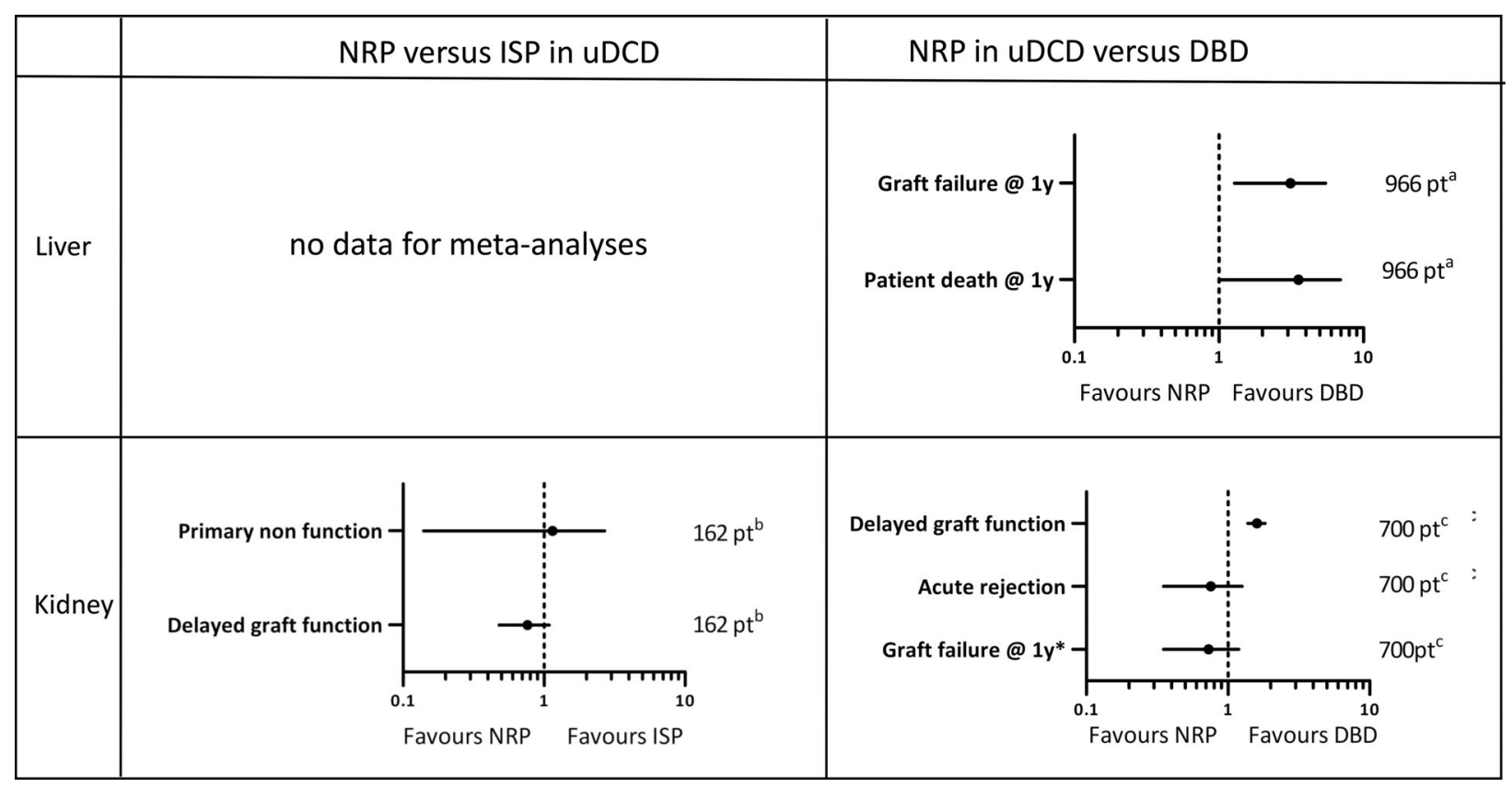

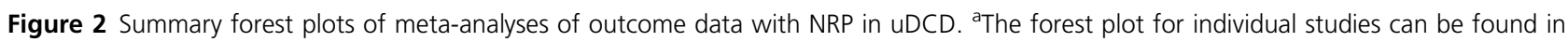
Fig. S3 [66,112]. ' The forest plot for individual studies can be found in Fig. S4 [51,52,117]. 'The forest plot for individual studies can be found in Figs S5 and S6 $[81,87,106]$. 
Compared with DBD, no difference in graft failure after NRP was observed (HR 0.65, 95\% CI 0.35-1.19; Figs 2 and S6).

Heart: One report described heterotopic heart transplantation after TA-NRP in a DBD donor experiencing a sudden cardiac arrest (Maastricht category IV) $[31,46]$. The transplanted heart was able to take over circulation after 5 days (Tables S14-S16).

\section{Regional perfusion in $\mathrm{CDCD}$}

\section{Hypothermic regional perfusion in $c D C D$}

Liver: One case report was identified describing a cDCD liver transplanted after $4 \mathrm{~h}$ of HRP followed by cold storage, with favourable follow-up at 2 years [119] (Tables S19 and S20).

Kidney: One case series [71] and one cohort study were identified [111] (Tables S21 and S22) Kidneys were cold stored. High PNF and DGF rates were described with variable graft survival rates, as low as $40 \%$.

\section{Normothermic regional perfusion in $C D C D$}

Liver: Eight primary studies were identified [38,53,6264,91,93,108] (Tables S19 and S20; Fig. 3). NRP livers were cold stored.

Graft function: Variable PNF (0-9\%) and EAD (0$36 \%)$ rates were reported. Meta-analysis showed nonsignificant reduction in PNF after NRP compared with ISP in CDCD (RR 0.67, 95\% CI 0.24-1.87; Figs 3 and S7), but event rate was low. Sensitivity analysis excluding livers undergoing subsequent ex situ hypothermic oxygenated perfusion (HOPE) did not change results (RR 0.43, 95\% CI 0.10-1.81). NRP lowered risk of EAD by $56 \%$ compared with ISP in DCD (RR $0.44,95 \%$ CI $0.26-0.76$ ), but there was considerable heterogeneity (Figs 3 and S7). Results without HOPE cases were similar (RR 0.55, 95\% CI 0.33-0.92). There was no evidence that NRP influenced the risk of hepatic artery thrombosis compared with ISP in CDCD (RR 1.15, 95\% CI 0.45-2.96; Figs 3 and S7); excluding HOPE cases did not change results (RR 1.05, 95\% CI 0.34-3.92).

Biliary complications: Consistently low IC rates (0$2 \%)$ were reported. Hessheimer et al. showed that NRP was independently associated with lower overall biliary complications (OR 0.14; 95\% CI 0.06-0.35) and lower IC (OR 0.11; 95\% CI 0.02-0.57) compared with ISP in CDCD [64]. Meta-analysis showed that NRP lowered the risk of any type of biliary strictures by $79 \%$ compared with ISP $\mathrm{cDCD}$ (RR $0.21,95 \%$ CI $0.10-0.36$;
Figs 3 and S8). When analysing IC and anastomotic strictures separately, NRP lowered risks by $75 \%$ (RR 0.25, 95\% CI 0.10-0.67; Figs 3 and S8) and 65\% (RR $0.35,95 \%$ CI $0.22-0.55$; Figs 3 and S8), respectively. Results were similar when HOPE cases were excluded (RR 0.15, 95\% CI 0.05-0.45 and RR 0.29, 95\% CI 0.150.57 , respectively). For IC, the anticipated absolute risk difference is 13 fewer (95\% CI 6-16 fewer) cases per 100 NRP cases compared with ISP CDCD liver transplants. For anastomotic biliary strictures, this is 15 fewer (95\% CI 10-18 fewer) cases per 100 NRP cases compared with ISP cDCD liver transplants.

Graft and patient survival: Graft survival was defined variably. Hessheimer et al. showed decreased risk of graft failure (including death with a functioning graft) with NRP (HR 0.39; 95\% CI 0.20-0.78) compared with ISP. Reported 1-year patient survival rates with NRP were $93 \%-94 \%$. Meta-analysis found no significant difference in mortality risk between NRP or ISP (HR 0.61, 95\% CI 0.33-1.12), though caution is needed when interpreting these data, as estimation methods had to be used (Figs 3 and S9) [33].

Kidney: Eleven primary studies were identified $[54,58,59,76,83,89,93,94,98,101,108]$ (Tables S21 and S22; Fig. 3). Most kidneys were cold stored with HMP in one study [89].

Graft function: Variable PNF (0-5.4\%) and DGF rates (0-40\%) were described. Compared with DBD, DGF rates after NRP were not different than in DBD (RR $0.83,95 \%$ CI $0.44-1.55$; Figs 3 and S10). One-year mean creatinine levels of $0.86-1.58 \mathrm{mg} / \mathrm{dl}$ and mean GFR of $52-73 \mathrm{ml} / \mathrm{min} / 1.73 \mathrm{~m}^{2}$ were reported.

Graft and patient survival: Graft survival was variably defined with reported 1-year graft and patient survival rates of $\geq 84 \%$ and $\geq 93 \%$, respectively.

Pancreas: Three primary studies reporting on seven pancreas transplants after NRP were identified with few outcome data presented $[55,83,93]$. All cases experienced immediate graft function. Reported 6-month and 1-year graft survival of $100 \%$ has been described $[55,83]$.

Heart: Five primary studies reporting on 18 heart transplants after TA-NRP were identified $[67,78,79,114,115]$, one with a comparator group in which hearts underwent ISP followed by ex situ perfusion [78] (Tables S23-S25). One case report mentions direct procurement of a heart with simultaneous A-NRP, followed by ex situ perfusion [86]. Although most hearts underwent ex situ normothermic perfusion, cases with static cold storage (15-117 $\mathrm{min})$ after TA-NRP have been described $[79,114,115]$. Reports on initial graft 


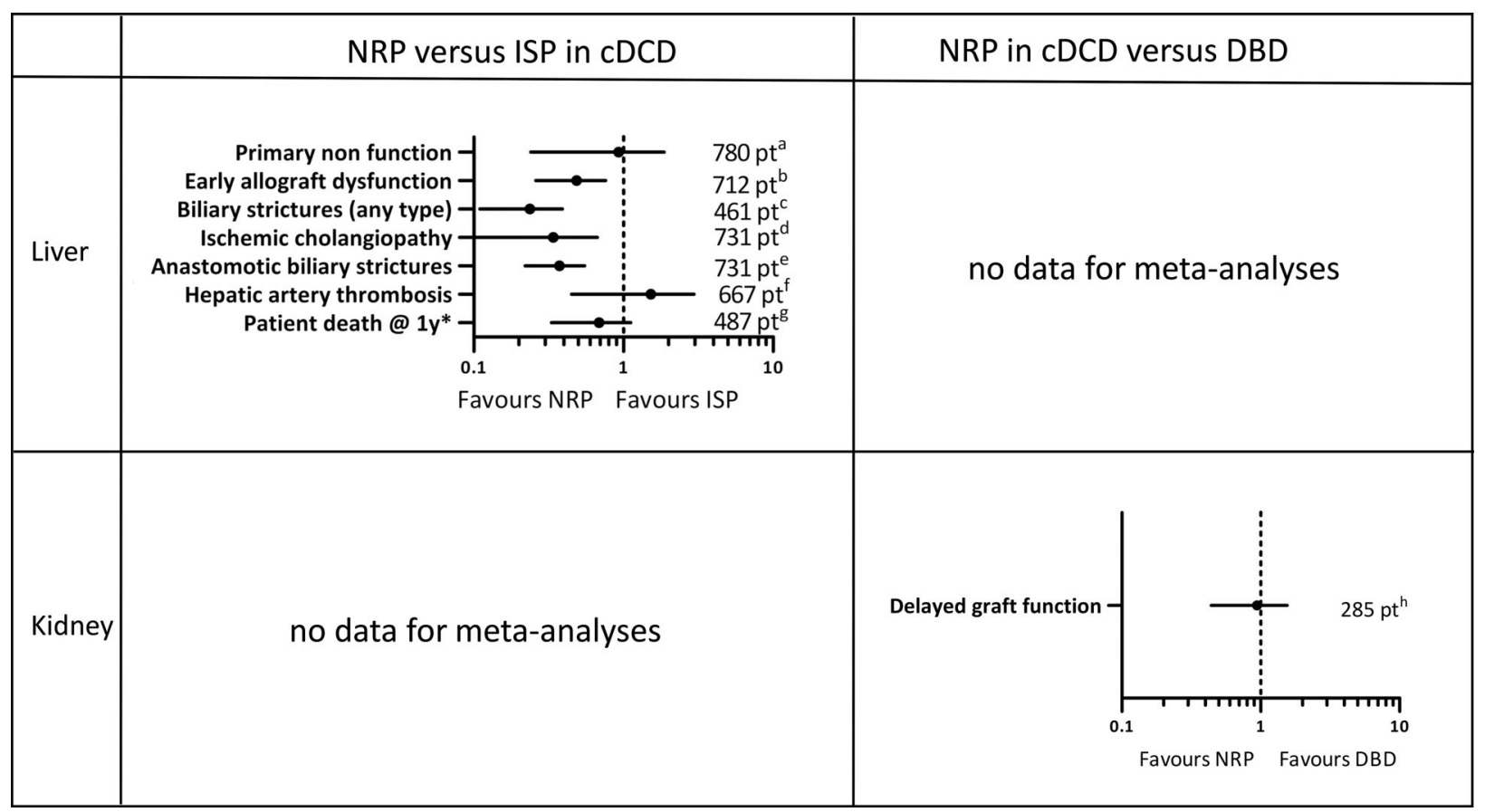

Figure 3 Summary forest plots of meta-analyses of outcome data with NRP in CDCD. ${ }^{a}$ The forest plot for individual studies can be found in

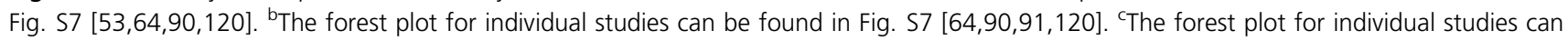
be found in Fig. $S 8[53,64,81,87,106,120]$. ${ }^{d}$ The forest plot for individual studies can be found in Fig. $58[38,62,63,93] .{ }^{e}$ The forest plot for individual studies can be found in Fig. S8 $[53,64,90,91,120] .{ }^{~}$ The forest plot for individual studies can be found in Fig. S7 [64,90,120]. ${ }^{9}$ The forest plot for individual studies can be found in Fig. $59[64,91,120] .{ }^{\text {h }}$ The forest plot for individual studies can be found in Fig. $\$ 10$ $[58,83,89]$.

function described mean cardiac indices of 2.0-2.53 l/ $\mathrm{min} / \mathrm{m}^{2}$, cardiac output of $3.95-4.8 \mathrm{l} / \mathrm{min}$, and ejection fraction of $50-74 \%$. Need for mechanical support varied $(0-17 \%)$. Table 25 summarizes dose and duration of pharmacological support. When compared with ISP followed by ex situ perfusion in CDCD, Messer et al. [78] reported a lower incidence of mechanical support after NRP, with slightly higher cardiac index and output, similar ejection fraction, and better patient survival at 3 months ( $100 \%$ vs. $86 \%)$, although recipients may not have been comparable. One-year graft survival and 3-month patient survival were $100 \%$.

Lung: Five primary studies [42,43,94,97], one with a DBD comparator group [82], were identified, reporting on 24 lung transplants, all ISP of lungs with simultaneous A-NRP (Tables S26 and S27). Though strictly these lungs were not transplanted after NRP, we include the results as they are relevant to NRP practice. Most lungs were cold stored, except for one case series with ex situ lung perfusion to assess viability [97]. We found no reports of lung transplants after TA-NRP. Limited information on post-transplant outcomes was reported. Compared with DBD, cDCD lungs retrieved during A-NRP seem to experience less PGD-1 (4.8\% vs. $7.4 \%$ ) and PGD-2 (4.8\% vs. 9.6\%) but more PGD-3 (19\% vs. $7.4 \%$ ) [82]. One-year graft survival rates were $84-100 \%$, with 2 -year patient survival rates of $90 \%$.

\section{Donor conversion and organ utilization rates}

No study was designed to investigate DCR after RP, and no direct comparisons with ISP were available. The definition of 'potential donor' differed amongst reports, making comparison difficult and the value of any calculated DCR questionable (Table S28). Kidney OURs for HRP of $43-88 \%$ were found. OURs calculated for NRP in $\mathrm{uDCD}$ were $25-100 \%$ for kidney and $9-38 \%$ for liver (Table S28); for NRP in cDCDs OURs were 60$100 \%$ for kidney, $25-100 \%$ for liver, $0-26 \%$ for pancreas, $0-60 \%$ for lung, and $78-100 \%$ for heart (Table S28). No direct comparison with ISP-DCD or DBD was possible.

\section{Discussion}

In DCD donation, RP has been advocated to tackle higher post-transplant complications and lower utilization rates. This systematic review shows that current 
evidence suggests that RP reduces certain posttransplant complications, though this finding is not universal. This is especially true for NRP and in particular for NRP in CDCD where there is evidence that NRP reduces the risk of both IC and anastomotic biliary strictures. Whether RP increases DCR and OUR compared with ISP in DCD or DBD requires further study, with standardized reporting of information related to potential, eligible, actual, and utilized donors [27].

In settings where uDCD has been successfully implemented, most organ preservation manoeuvres have been initiated before next-of-kin have arrived at the hospital and specific consent for donation has been given. Preservation manoeuvres applied in uDCD need to be maintainable for some hours and should leave the body as intact as possible. This is achievable by RP with placement of catheters in the groin but not by (thoraco-) laparotomy. Limited available evidence, dating from 2005 or earlier, suggests some benefit of HRP. The lack of reports on HRP after 2005 suggests that the technique is now clinically less relevant and seems to have been replaced by NRP. Transplantation of $\mathrm{uDCD}$ livers and kidneys after NRP is associated with inferior graft and patient survival relative to DBD. Some kidney registry analyses suggest that NRP decreases PNF and DGF risks compared with ISP in uDCD. No studies comparing NRP with ISP in UDCD for liver are reported, reflecting hesitancy to transplant uDCD livers without some form of perfusion (in situ or ex situ). Therefore, relevant comparisons of uDCD-NRP with uDCD-ISP outcomes could not be performed. Experience with $\mathrm{uDCD}$ lung transplantation in RP-settings is limited with early and late outcomes that appear inferior to those of $\mathrm{CDCD}$ lungs. As $\mathrm{uDCD}$ often implies a cardiac cause of death, it is unsurprising that $\mathrm{uDCD}$ heart transplantation, and the use of RP, is nonexistent. While transplantation of uDCD liver, kidneys, and lungs after NRP should not necessarily be avoided altogether, these organs should be used with caution, weighing risks of continued waiting against risks of utilizing uDCD grafts, even with RP techniques.

In CDCD, NRP has taken over from HRP techniques and current evidence suggests improved outcomes for liver and kidney compared with ISP in CDCD. As NRP requires the placement of cannulae, the donor warm ischaemia time might be longer compared with ISP, though this appears limited to about $10 \mathrm{~min}$ or less (Table S29). Limited evidence on HRP, dating from 2005 or earlier, reports high kidney PNF and DGF rates, with no comparison to ISP or DBD available and only one liver transplant has been described. For NRP, more evidence is available and comparison with ISP in CDCD is possible. We found no evidence that NRP reduces risks of PNF or mortality after liver transplantation compared with ISP in CDCD. However, our meta-analyses suggest that NRP leads to a significant reduction in overall biliary complications (IC by $75 \%$, anastomotic strictures by 65\%) compared with ISP in cDCD. IC is the most feared long-term complication in DCD livers, with some series reporting up to $100 \%$ five-year graft loss among grafts experiencing IC [124]. In kidney transplantation, variable PNF and DGF rates are described. A direct comparison with ISP in DCD, published very recently, suggests reduced DGF risk with NRP [125]. We found no evidence that risk of DGF after NRP is different compared with DBD, while it is well-known that ISP leads to higher DGF rates compared with DBD [17]. Kidney graft survival rates with NRP appear good, but variable definitions are used. Pancreas transplantation after NRP is feasible and safe, but large series have not been reported. Though limited in numbers, outcomes for CDCD heart transplantation are comparable to $\mathrm{DBD}$. One series compares recovery after TA-NRP and use of ISP in CDCD followed by ex situ perfusion, with an apparent advantage for the former. Early graft survival, PGD rates, and late chronic lung allograft dysfunction of $\mathrm{CDCD}$ lung transplantation when there has been A-NRP are similar to ISP in $\mathrm{CDCD}$ and DBD series. Technical issues involving thoracic haemostasis after lung removal when NRP continues below the diaphragm exist. One case of lung transplantation after TA-NRP has been recently reported, showing feasibility [126]. With wider use of TA-NRP, and the known negative effects of cardiopulmonary bypass on the lung, one might imagine a small disadvantage for the lung with wider use of TA-NRP. Especially since the ischaemic tolerance of the lung, reflected by similar outcome after $\mathrm{CDCD}$ and DBD lung transplantation [21,22], appears to make RP unnecessary for DCD lungs. In addition, concerns of brain reperfusion during TA-NRP exist. One case of TA-NRP with subsequent haemodynamic instability due to presumed cytokine washout has been described, though the authors recognize a Cushingoid response due to an inadvertent cerebral perfusion could not be excluded [114]. Solutions to this problem have been provided in a recent UK/Canadian consensus [127].

An unresolved question is whether reversibility of ischaemia and restoration of function after (T)A-NRP reduce the detrimental impact of subsequent cold ischaemia. With increasing evidence that ex situ perfusion improves outcomes in DCD organs retrieved after 
ISP and allows for additional viability testing [128-131], this is an important issue that requires further research. As PNF rates in uDCD remain high, ex situ liver perfusion might allow better graft selection and kidneys might benefit from improved preservation with ex situ perfusion. For the heart, static cold storage has only been used when cold ischaemia was very short, with the donor at or close to the recipient centre. If TA-NRP followed by cold storage were found to be safe and effective, its use would help avoid the cost and complexity of routine ex situ heart perfusion. Furthermore, comparisons of NRP with ex situ preservation techniques are needed. We found only one direct comparison of NRP with ISP followed by HOPE in CDCD livers showing similar post-transplant outcomes, though cautions are warranted as NRP and ISP-HOPE cases were performed in different countries which might have led to bias [90].

As with all systematic reviews, it is possible that not all relevant articles were found or that relevant studies were published after the search. In the absence of RCTs, the quality of the published evidence is limited and risk of publication bias is high. The conclusions of this review should, therefore, be interpreted with caution, and, ideally, RCTs would contribute to the evidence. Reticence to performing expensive and logistically challenging RCTs [132,133] comparing ISP and NRP in CDCD has been observed as the current body of evidence on NRP suggests loss of equipoise for the liver, with data pointing towards reduced posttransplant biliary complications, and no evidence of detrimental effects for other abdominal organs. Furthermore, NRP offers the opportunity to slow down, observe, and evaluate organs more extensively via evolution of perfusate lactate, transaminases, and amylase, as well bile production, diuresis, and cardiac ultrasound and pressure measurements and possibly reduces injury during recovery. Indeed, the ISP-DCD process is a stressful rush to get organs cooled, perfused and retrieved as quickly as possible, leading to increased rates of organ injury $[134,135]$.

Well-designed and maintained (inter)national registries might provide the basis for observational studies, with the application of appropriate statistical methods that allow causal inference [136]. These registries would benefit from standardized data collection for all organs recovered from the donor and standardized outcome definitions to allow more straightforward data comparisons and meta-analyses.

In conclusion, this systematic review and metaanalyses show RP is a feasible and safe alternative to ISP in uDCDs and cDCDs (Box 2). Reports on HRP date from 2005 or earlier and this technique seems to have been replaced by NRP. NRP appears to reduce some post-transplant complications, especially in the setting of cDCD liver transplantation where evidence suggests the risk of IC and anastomotic biliary strictures is reduced by NRP. Comparisons for kidney and pancreas, especially with ISP in DCD, are needed, but there is no evidence to suggest NRP is detrimental. Outcomes of thoracic organs after TA-NRP require additional data to assess safety and efficacy. Whether NRP increases donor and organ utilization needs further research.

\section{Authorship}

JDB, KVDD, and IJ: designed the study. JDB, KVDD, LHMP and SRK: performed the systematic search and screened the records. JDB and KVDD: extracted the data. LHMP and MIB: performed quality assessment. LHMP and SRK: assessed the certainty of the evidence. IJ: analysed the data and wrote the paper. JDB, KVDD, LHMP, MIB, JHD, AJH, HJANK, SRK, APN, DP, CJEW and FR: provided critical feedback.

\section{Funding}

This work was performed with the support by the European Society of Organ Transplantation (ESOT) within the remit of the Transplant Learning Journey 2.0.

Box 2. Summary of findings

1. Available evidence is associated with a significant potential for bias.

2. Hypothermic and normothermic regional perfusion are feasible and safe in uncontrolled and controlled DCD donation.

3. Normothermic regional perfusion appears to have replaced hypothermic regional perfusion in clinical practice.

4. Normothermic regional perfusion reduces some post-transplant complications, especially biliary strictures in controlled DCD liver transplantation.

5. It is unknown whether the use of ex situ organ perfusion after normothermic regional perfusion provides additional benefit.

6. Effect of normothermic regional perfusion on donor and organ utilization compared to in-situ cold preservation in DCD and DBD needs further investigation.

7. There is a need for high quality evidence via trials and well-designed (inter)national registries. 


\section{Conflicts of interest}

$\mathrm{AJH}$ has received research funding and consultancy fees from Guanguong Shunde Innovative Design Institute. JHD has received research support as an Unrestricted Educational Grant from XVIVO Perfusion. SRK has received consultancy fees from OrganOx Ltd and speaker fees from Sandoz. DP has received speaker fees from Novartis. CJEW has received consultancy fees from Nephro Health, Jazz Pharmaceuticals, and speaker fees from OrganOx Ltd. IJ has received speaker fees from XVIVO Perfusion. All other authors have no conflicts of interest to report.

\section{Acknowledgements}

We would like to thank Thomas Vandendriessche, Kristel Paque, and Krizia Tuand, the biomedical reference librarians of the KU Leuven Libraries - 2Bergen - Learning Centre Désiré Collen (Leuven, Belgium) for their help in conducting the systematic literature search. We also thank Veerle Heedfeld and Tine Wylin for their help with data extraction and Sofie Vets for proofreading the appendix. JDB holds a $\mathrm{PhD}$ fellowship fundamental research $(1152820 \mathrm{~N})$ from The Research Foundation Flanders (FWO). The University of Cambridge has received salary support in respect of CJEW from the National Health Service in the East of England through the Clinical Academic Reserve.

\section{SUPPORTING INFORMATION}

Additional supporting information may be found online in the Supporting Information section at the end of the article.

Appendix S1. Search strategies.

Appendix S2. Inclusion and exclusion criteria for studies.

Appendix S3. Selection of primary study report.

Appendix S4. Clinical heterogeneity and grouping of studies for meta-analyses.

Appendix S5. Determination of regional perfusion (RP) temperature when not mentioned in the paper.

Appendix S6. Characteristics of the 105 eligible studies.

Figure S1. Proportion of DCD donors to the overall deceased donor activity in 2007 and 2017.

Figure S2. Percentage of organs used in DCD and DBD donation.
Figure S3. Forest plot of (panel a) graft failure and (panel b) mortality in uDCD liver transplantation after NRP compared to DBD liver transplantation.

Figure S4. Forest plot of (panel a) primary non-function and (panel b) delayed graft function in uDCD kidney transplantation after NRP compared to ISP.

Figure S5. Forest plot of (panel a) delayed graft function; (panel b) acute rejection, and (panel c) GFR in uDCD kidney transplantation after NRP compared with DBD.

Figure S6. Forest plot of graft survival in uDCD kidney transplantation after NRP compared to DBD.

Figure S7. Forest plot of (panel a) primary non-function, (panel b) early allograft dysfunction, and (panel c) hepatic artery thrombosis in CDCD liver transplantation after NRP compared to ISP.

Figure S8. Forest plot of (panel a) any type of biliary stricture, (panel b) ischaemic cholangiopathy, and (panel c) anastomotic biliary strictures in CDCD liver transplantation after NRP compared with ISP.

Figure S9. Forest plot of mortality in $\mathrm{CDCD}$ liver transplantation after NRP compared with ISP.

Figure S10. Forest plot of delayed graft function in CDCD kidney transplantation after NRP compared with DBD.

Table S1. Overview of articles by country, study type, origin of the data set, study groups, RP temperature and organ for which post-transplant outcome measures are available.

Table S2. Quality assessment of case series according to the NIH quality assessment score.

Table S3. Quality assessment of cohort studies according to the NIH quality assessment score.

Table S4. Quality assessment of case-control studies according to the NIH quality assessment score.

Table S5. Primary study report for studies reporting on outcomes after liver transplantation.

Table S6. Primary study report for studies reporting on outcomes after kidney transplantation.

Table S7. Primary study report for studies reporting on outcomes after pancreas transplantation.

Table S8. Primary study report for studies reporting on outcomes after heart transplantation.

Table S9. Primary study report for studies reporting on outcomes after lung transplantation.

Table S10. Early clinical outcomes after uDCD liver transplantation.

Table S11. Biliary complications and graft and patient survival after uDCD liver transplantation.

Table S12. Clinical outcomes after uDCD kidney transplantation. 
Table S13. Graft function after uDCD kidney transplantation.

Table S14. Clinical outcomes after uDCD heart transplantation.

Table S15. Need for mechanical support and cardiac performance indices early after uDCD heart transplantation.

Table S16. Duration and dosage of pharmacological support after uDCD heart transplantation.

Table S17. Clinical outcome data after uDCD lung transplantation.

Table S18. Need for mechanical support, lung performance indices early after uDCD lung transplantation.

Table S19. Early clinical outcomes after cDCD liver transplantation.

Table S20. Biliary complications and graft and patient survival after cDCD liver transplantation.

Table S21. Clinical outcomes after cDCD kidney transplantation.
Table S22. Graft function after cDCD kidney transplantation.

Table S23. Clinical outcomes after cDCD heart transplantation.

Table S24. Need for mechanical support and cardiac performance indices early after CDCD heart transplantation.

Table S25. Duration and dosage of pharmacological support after CDCD heart transplantation.

Table S26. Clinical outcome data after cDCD lung transplantation.

Table S27. Need for mechanical support, lung performance indices early after CDCD lung transplantation.

Table S28. Donor conversion rates and organ utilization rates in RP solid organ transplantation.

Table S29. Reported warm ischaemia times (and their definitions) in studies reporting on NRP compared to ISP in controlled DCD.

Table S30. Characteristics of the 105 eligible studies.

\section{REFERENCES}

1. Lomero M, Gardiner D, Coll E, et al. Donation after circulatory death today: an updated overview of the European landscape. Transpl Int 2020; 33: 76.

2. Orman ES, Barritt AS, Wheeler SB, Hayashi PH. Declining liver utilization for transplantation in the United States and the impact of donation after cardiac death. Liver Transpl 2013; 19: 59.

3. Berney T, Boffa C, Augustine T, et al. Utilization of organs from donors after circulatory death for vascularized pancreas and islet of Langerhans transplantation: recommendations from an expert group. Transpl Int 2016; 29: 798.

4. Jochmans I, van Rosmalen M, Pirenne J, Samuel U. Adult liver allocation in eurotransplant. Transplantation 2017; 101: 1542.

5. Domínguez-Gil B, Haase-Kromwijk B, Van Leiden $\mathrm{H}$, et al. Current situation of donation after circulatory death in European countries. Transpl Int 2011; 24: 676.

6. Heylen L, Jochmans I, Samuel U, et al. The duration of asystolic ischemia determines the risk of graft failure after circulatory-dead donor kidney transplantation: a Eurotransplant cohort study. Am J Transplant 2018; 18: 881.

7. Bastos-Neves D, Salvalaggio PRO, Almeida MD. Risk factors, surgical complications and graft survival in liver transplant recipients with early allograft dysfunction. Hepatobiliary Pancreat Dis Int 2019; 18: 423.

8. Coffey JC, Wanis KN, Monbaliu D, et al. The influence of functional warm ischemia time on DCD liver transplant recipients' outcomes. Clin Transplant 2017; 31: e13068.

9. Mourad MM, Algarni A, Liossis C, Bramhall SR. Aetiology and risk factors of ischaemic cholangiopathy after liver transplantation. World J Gastroenterol 2014; 20: 6159.

10. Snoeijs MGJ, Dekkers AJE, Buurman WA, et al. In situ preservation of kidneys from donors after cardiac death: results and complications. Ann Surg 2007; 246: 844.

11. Hessheimer AJ, García-Valdecasas JC, Fondevila C. Abdominal regional insitu perfusion in donation after circulatory determination of death donors. Curr Opin Organ Transplant 2016; 21 : 322.

12. Tsui SSL, Oniscu GC. Extending normothermic regional perfusion to the thorax in donors after circulatory death. Curr Opin Organ Transplant 2017; 22: 245.

13. Arias-Diaz J, Alvarez J, Gomez M, et al. Changes in adenine nucleotides and lipid hydroperoxides during normothermic cardiopulmonary bypass in a porcine model of type II non- heart-beating donor. Transplant Proc 1997; 29: 3486.

14. Gonzalez FX, García-Valdecasas JC, López-Boado MA, et al. Adenine nucleotide liver tissue concentrations from non-heart-beating donor pigs and organ viability after liver transplantation. Transplant Proc 1997; 29: 3480.

15. Net M, Valero R, Almenara R, et al. The effect of normothermic recirculation is mediated by ischemic preconditioning in NHBD liver transplantation. Am $J$ Transplant 2005; 5: 2385.

16. Jay CL, Lyuksemburg V, Ladner DP, et al. Ischemic cholangiopathy after controlled donation after cardiac death liver transplantation: a metaanalysis. Ann Surg 2011; 253: 259.

17. Summers DM, Watson CJE, Pettigrew GJ, et al. Kidney donation after circulatory death $(\mathrm{DCD})$ : state of the art. Kidney Int 2015; 88: 241.

18. Summers DM, Pettigrew GJ. Kidney transplantation following uncontrolled donation after circulatory death. Curr Opin Organ Transplant 2020; 25: 144.

19. Shahrestani S, Webster AC, Lam VWT, et al. Outcomes from pancreatic transplantation in donation after cardiac death: a systematic review and meta-analysis. Transplantation 2017; 101: 122

20. Callaghan CJ, Ibrahim M, Counter C, et al. Outcomes after simultaneous 
pancreas-kidney transplantation from donation after circulatory death donors: a UK registry analysis. Am J Transplant 2021. https://doi.org/10. 1111/ajt.16604 (epub ahead of print).

21. Van Raemdonck D, Keshavjee S, Levvey $\mathrm{B}$, et al. Donation after circulatory death in lung transplantation-five-year followup from ISHLT registry. $J$ Heart Lung Transplant 2019; 38: 1235.

22. Palleschi A, Rosso L, Musso V, Rimessi A, Bonitta G, Nosotti M. Lung transplantation from donation after controlled cardiocirculatory death. Systematic review and meta-analysis. Transplant Rev 2020; 34: 100513.

23. Dhital KK, Chew HC, Macdonald PS. Donation after circulatory death heart transplantation. Curr Opin Organ Transplant 2017; 22: 189.

24. van de Leemkolk FEM, Schurink IJ, Dekkers OM, et al. Abdominal normothermic regional perfusion in donation after circulatory death: a systematic review and critical appraisal. Transplantation 2020; 104: 1776.

25. Jochmans I, Hessheimer AJ, Neyrinck $\mathrm{AP}$, et al. Consensus statement on normothermic regional perfusion in donation after circulatory death: report from the European Society for Organ Transplantation's Transplant Learning Journey. Transpl Int 2021 in press. https://doi.org/10.1111/tri. 13951 (epub ahead of print).

26. Stroup DF, Berlin JA, Morton SC, et al. Meta-analysis of observational studies in epidemiology: a proposal for reporting. Meta-analysis of observational studies in epidemiology (MOOSE) group. JAMA 2000; 283: 2008.

27. Domínguez-Gil B, Delmonico FL, Shaheen FAM, et al. The critical pathway for deceased donation: reportable uniformity in the approach to deceased donation. Transpl Int 2011; 24: 373.

28. National Institutes of Health; Study Quality Assessment Tools. Available at http://www.nhlbi.nih.gov/healthtopics/studyquality-assessment-tools. Accessed July 2020.

29. Lim HJ, Lee YJ, Nam JH, Chung S, Shin S. Temperature-dependent threshold shear stress of red blood cell aggregation. J Biomech 2010; 43: 546.

30. Eckmann DM, Bowers S, Stecker M, Cheung AT. Hematocrit, volume expander, temperature, and shear rate effects on blood viscosity. Anesth Analg 2000; 91: 539.

31. Thuong M, Ruiz A, Evrard P, et al. New classification of donation after circulatory death donors definitions and terminology. Transpl Int 2016; 29: 749 .
32. Wan X, Wang W, Liu J, Tong T. Estimating the sample mean and standard deviation from the sample size, median, range and/or interquartile range. BMC Med Res Methodol 2014; 14: 135.

33. Tierney JF, Stewart LA, Ghersi D, Burdett S, Sydes MR. Practical methods for incorporating summary timeto-event data into meta-analysis. Trials 2007; 8: 16.

34. Available at www.gradepro.org. Accessed July 2020

35. Abboud I, Viglietti D, Antoine C, et al. Preliminary results of transplantation with kidneys donated after cardiocirculatory determination of death: a French single-centre experience. Nephrol Dial Transplant 2012; 27: 2583.

36. Alvarez J, del Barrio R, Arias J, et al. Non-heart-beating donors from the streets: an increasing donor pool source. Transplantation 2000; 70: 314.

37. Alvarez-Rodriguez J, Del Barrio-Yesa $\mathrm{R}$, Torrente-Sierra J, Prats-Sanchez MD, Guzman AB. Posttransplant long-term outcome of kidneys obtained from asystolic donors maintained under extracorporeal cardiopulmonary bypass. Transplant Proc 1995; 27: 2903.

38. Antoine C, Jasseron C, Dondero F, Savier E. Liver transplantation from controlled donors after circulatory death using normothermic regional perfusion: an initial French experience. Liver Transpl 2020; 26: 1516.

39. Antoine C, Savoye E, Gaudez F, et al. Kidney transplant from uncontrolled donation after circulatory death: contribution of normothermic regional perfusion. Transplantation 2020; 104: 130.

40. Arias J, Alvarez J, Gomez $\mathrm{M}$, et al. Successful renal transplantation with kidneys from asystolic donors maintained under extracorporeal cardiopulmonary bypass: 6-month follow-up. Transplant Proc 1991; 23: 2581.

41. Arnoux V, Dorez D, Muller M, et al. Non-heart-beating renal donors: organization in a non-university hospital. Prog Urol 2014; 24: 13.

42. Butler AJ, Randle LV, Watson CJ. Normothermic regional perfusion for donation after circulatory death without prior heparinization. Transplantation 2014; 97: 1272.

43. Caralt M, Bello I, Sandiumenge A, et al. "Non-touch" vena cava technique as an improvement in combined lung and liver procurement in controlled donation after circulatory death. Transplant Proc 2019; 51: 9.
44. Champigneulle B, Fieux F, Cheisson $\mathrm{G}$, et al. French survey of the first three-years of liver transplantation activity from uncontrolled donors deceased after cardiac death. Anaesth Crit Care Pain Med 2015; 34: 35.

45. Chen K-H, Tsai M-K, Ko W-J, et al. Renal transplantation from non-heartbeating donors with extracorporeal membrane oxygenation: preliminary results. Transplant Proc 2000; 32: 1743.

46. Chiu KM, Lin TY, Chu SH. Successful heterotopic heart transplant after cardiopulmonary bypass rescue of an arrested donor heart. Transplant Proc 2006; 38: 1514.

47. De Carlis L, Lauterio A, De Carlis R, Ferla F, Di Sandro S. Donation after cardiac death liver transplantation after more than 20 minutes of circulatory arrest and normothermic regional perfusion. Transplantation 2016; 100: e21.

48. De Carlis R, Di Sandro S, Lauterio A, et al. Liver grafts from donors after circulatory death on regional perfusion with extended warm ischemia compared with donors after brain death. Liver Transpl 2018; 24: 1523.

49. De Carlis R, Di Sandro S, Lauterio A, et al. Successful donation after cardiac death liver transplants with prolonged warm ischemia time using normothermic regional perfusion. Liver Transpl 2017; 23: 166.

50. del Río F, Andrés A, Padilla M, et al. Kidney transplantation from donors after uncontrolled circulatory death: the Spanish experience. Kidney Int 2019; 95: 420 .

51. Delsuc C, Faure A, Berthiller J, et al. Uncontrolled donation after circulatory death: comparison of two kidney preservation protocols on graft outcomes. BMC Nephrol 2018; 19: 3.

52. Demiselle J, Augusto J-F, Videcoq M, et al. Transplantation of kidneys from uncontrolled donation after circulatory determination of death: comparison with brain death donors with or without extended criteria and impact of normothermic regional perfusion. Transpl Int 2016; 29: 432.

53. Ding G-Y, Zhao $\mathrm{Y}, \mathrm{Wu} \mathrm{W}$, et al. In situ normothermic regional perfusion for liver donation from China category III (organ donation after brain death followed by circulatory death): a single-center cohort study. Exp Clin Transplant 2020; 18: 83.

54. Farney AC, Hines MH, al-Geizawi S, Rogers J, Stratta RJ. Lessons learned from a single center's experience with 134 donation after cardiac death donor kidney transplants. J Am Coll Surg 2011; 212: 440; discussion 51-3. 
55. Farney AC, Singh RP, Hines $M H$, et al. Experience in renal and extrarenal transplantation with donation after cardiac death donors with selective use of extracorporeal support. $J$ Am Coll Surg 2008; 206: 1028; discussion 37.

56. Fondevila C, Hessheimer AJ, Flores E, et al. Applicability and results of Maastricht type 2 donation after cardiac death liver transplantation. Am J Transplant 2012; 12: 162.

57. Fondevila C, Hessheimer AJ, Ruiz A, et al. Liver transplant using donors after unexpected cardiac death: novel preservation protocol and acceptance criteria. Am J Transplant 2007; 7: 1849.

58. Foss S, Nordheim E, Sørensen DW, et al. First scandinavian protocol for controlled donation after circulatory death using normothermic regional perfusion. Transplant Direct 2018; 4: e366.

59. Georgiades F, Hosgood SA, Butler AJ, Nicholson ML. Use of ex vivo normothermic machine perfusion after normothermic regional perfusion to salvage a poorly perfused DCD kidney. Am J Transplant 2019; 19: 3415.

60. González-Aguirre D, Jaramillo-Gante MÁ, Muruato-Araiza S, SánchezAguilar JM, de Oca-Arce JLM. Renal transplantation in asystole Maastricht II. Report of the first case in Mexico. Gac Med Mex 2014; 150: 345.

61. Gravel MT, Arenas JD, Chenault R 2nd, et al. Kidney transplantation from organ donors following cardiopulmonary death using extracorporeal membrane oxygenation support. Ann Transplant 2004; 9: 57.

62. Hagness M, Foss S, Sørensen DW, et al. Liver transplant after normothermic regional perfusion from controlled donors after circulatory death: the Norwegian experience. Transplant Proc 2019; 51: 475.

63. Herrero Torres MA, Domniguez Bastante M, Molina Raya A, et al. Eight years of extracorporeal membrane oxygenation in liver transplantation: our experience. Transplant Proc 2020; 52: 572.

64. Hessheimer AJ, Coll E, Torres F, et al. Normothermic regional perfusion vs. super-rapid recovery in controlled donation after circulatory death liver transplantation. $J$ Hepatol 2019; 70: 658 .

65. Jiménez-Galanes S, Meneu-Diaz MJC, Elola-Olaso AM, et al. Liver transplantation using uncontrolled nonheart-beating donors under normothermic extracorporeal membrane oxygenation. Liver Transpl 2009; 15: 1110.
66. Jiménez-Romero C, Manrique A, Calvo J, et al. Liver transplantation using uncontrolled donors after circulatory death: a 10-year single-center experience. Transplantation 2019; 103: 2497.

67. Khushnood A, Butt TA, Jungschleger $\mathrm{J}$, et al. Paediatric donation after circulatory determined death heart transplantation using donor normothermic regional perfusion and ex situ heart perfusion: a case report. Pediatr Transplant 2019; 23: e13536.

68. Ko WJ, Chen YS, Chen RJ, Lai MK, Lee PH. Non-heart-beating donors under extracorporeal membrane oxygenation support. Transplant Proc 2002; 34: 2600.

69. Ko WJ, Chen YS, Tsai PR, Lee PH. Extracorporeal membrane oxygenation support of donor abdominal organs in non-heart-beating donors. Clin Transplant 2000; 14: 152.

70. Koyama I, Hoshino T, Nagashima N, Adachi H, Ueda K, Omoto R. A new approach to kidney procurement from non-heart-beating donors: core cooling on cardiopulmonary bypass. Transplant Proc 1989; 21: 1203.

71. Koyama I, Shinozuka N, Miyazawa M, Watanabe T. Total body cooling using cardiopulmonary bypass for procurement from non-heart-beating donors. Transplant Proc 2002; 34: 2602.

72. Koyama I, Shinozuka N, Watanabe T, et al. Utilization of kidneys from non-heart-beating donors by portable cardiopulmonary bypass. Transplant Proc 1997; 29: 3550.

73. Lazzeri C, Bonizzoli M, Fulceri GE, et al. Utilization rate of uncontrolled donors after circulatory death-a 3year single-center investigation. Clin Transplant 2020; 34: e13896.

74. Lee C-Y, Tsai M-K, Ko W-J, et al. Expanding the donor pool: use of renal transplants from non-heartbeating donors supported with extracorporeal membrane oxygenation. Clin Transplant 2005; 19: 383.

75. Lee JH, Hong SY, Oh CK, Hong YS, Yim H. Kidney transplantation from a donor following cardiac death supported with extracorporeal membrane oxygenation. J Korean Med Sci 2012; 27: 115.

76. Li J-F, Liu J, Guo T, et al. Kidney transplantation from pediatric donors in a single Chinese center. Cell Biochem Biophys 2014; 70: 1713.

77. Matillon X, Danjou F, Petruzzo P, et al. Hypothermic pulsatile preservation of kidneys from uncontrolled deceased donors after cardiac arrest a retrospective study. Transpl Int 2017; 30: 1284.
78. Messer S, Page A, Axell R, et al. Outcome after heart transplantation from donation after circulatory-determined death donors. J Heart Lung Transplant 2017; 36: 1311.

79. Messer S, Page A, Colah S, et al. Human heart transplantation from donation after circulatory-determined death donors using normothermic regional perfusion and cold storage. $J$ Heart Lung Transplant 2018; 37: 865.

80. Messer SJ, Axell RG, Colah S, et al. Functional assessment and transplantation of the donor heart after circulatory death. J Heart Lung Transplant 2016; 35: 1443.

81. Miñambres E, Rodrigo E, Suberviola $\mathrm{B}$, et al. Strict selection criteria in uncontrolled donation after circulatory death provide excellent long-term kidney graft survival. Clin Transplant 2020; 34: e14010.

82. Miñambres E, Ruiz P, Ballesteros MA, et al. Combined lung and liver procurement in controlled donation after circulatory death using normothermic abdominal perfusion. Initial experience in two Spanish centers. Am J Transplant 2020; 20: 231.

83. Miñambres E, Suberviola B, Dominguez-Gil B, et al. Improving the outcomes of organs obtained from controlled donation after circulatory death donors using abdominal normothermic regional perfusion. Am J Transplant 2017; 17: 2165.

84. Miranda-Utrera N, Medina-Polo J, Pamplona $\mathrm{M}$, et al. Donation after cardiac death: results of the SUMMA 112 - Hospital 12 de Octubre program. Clin Transplant 2013; 27: 283.

85. Miranda-Utrera N, Medina-Polo J, Pamplona-Casamayor $\mathrm{M}$, et al. Uncontrolled non-heartbeating donors (types i-ii) with normothermic recirculation vs. heartbeating donors: evaluation of functional results and survival. Actas Urol Esp 2015; 39: 429.

86. Mohite PN, Garcia Saez D, Butler AJ, Watson CJE, Simon A. Direct procurement of donor heart with normothermic regional perfusion of abdominal organs. Ann Thorac Surg 2019; 108: 597.

87. Molina M, Guerrero-Ramos F, Fernández-Ruiz $\mathrm{M}$, et al. Kidney transplant from uncontrolled donation after circulatory death donors maintained by nECMO has long-term outcomes comparable to standard criteria donation after brain death. Am J Transplant 2019; 19: 434.

88. Mori G, Cerami C, Facchini F, et al. Kidney transplantation from circulatory death donors: monocentric experience. Transplant Proc 2019; 51: 2865. 
89. Mori G, Solazzo A, Tonelli L, et al. Comparison between kidney transplantation after circulatory death and after brain death: a monocentric retrospective study after 1 year of follow-up. Transplant Proc 2020; 52: 1536.

90. Muller X, Mohkam K, Mueller M, et al. Hypothermic oxygenated perfusion versus normothermic regional perfusion in liver transplantation from controlled donation after circulatory death: first international comparative study. Ann Surg 2020; 272: 751.

91. Muñoz DC, Pérez BS, Martínez MP, et al. Does normothermic regional perfusion improve the results of donation after circulatory death liver transplantation? Transplant Proc 2020; 52: 1477.

92. Olivieri T, Magistri P, Guidetti C, et al. University of modena experience with liver grafts from donation after circulatory death: what really matters in organ selection? Transplant Proc 2019; 51: 2967.

93. Oniscu GC, Randle LV, Muiesan P, et al. In situ normothermic regional perfusion for controlled donation after circulatory death - the United Kingdom experience. Am J Transplant 2014; 14: 2846.

94. Oniscu GC, Siddique A, Dark J. Dual temperature multi-organ recovery from a Maastricht category III donor after circulatory death. Am J Transplant 2014; 14: 2181.

95. Otero A, Gómez-Gutiérrez M, Suárez $\mathrm{F}$, et al. Liver transplantation from Maastricht category 2 non-heartbeating donors. Transplantation 2003; 76: 1068.

96. Otero A, Gómez-Gutiérrez M, Suárez $\mathrm{F}$, et al. Liver transplantation from maastricht category 2 non-heartbeating donors: a source to increase the donor pool? Transplant Proc 2004; 36: 747.

97. Palleschi A, Tosi D, Rosso L, et al. Successful preservation and transplant of warm ischaemic lungs from controlled donors after circulatory death by prolonged in situ ventilation during normothermic regional perfusion of abdominal organs. Interact Cardiovasc Thorac Surg 2019; 29: 699.

98. Palomo-López N, Martín-Sastre S, Martín-Villén L, et al. Normothermic regional perfusion and donation after circulatory death (controlled and uncontrolled): metabolic differences and kidney transplantation evolution. Transplant Proc 2019; 51: 3044.

99. Peris A, Fulceri GE, Lazzeri C, et al. Delayed graft function and perfusion parameters of kidneys from uncontrolled donors after circulatory death. Perfusion 2021; 36: 299.

100. Puślecki M, Ligowski M, Stefaniak S, et al. "Extracorporeal membrane oxygenation for greater Poland" program: how to save lives and develop organ donation? Transplant Proc 2018; 50: 1957.

101. Ravaioli M, De Pace V, Comai G, et al. Preliminary experience of sequential use of normothermic and hypothermic oxygenated perfusion for donation after circulatory death kidney with warm ischemia time over the conventional criteria - a retrospective and observational study. Transpl Int 2018; 31: 1233.

102. Reznik A, Plotnikova O, Skvortsov A, Skoblov M, Reznik O, Baranova A. Reperfusion activates AP-1 and heat shock response in donor kidney parenchyma after warm ischemia. Biomed Res Int 2018; 2018: 5717913.

103. Reznik O, Bagnenko S, Scvortsov A, et al. The use of in-situ normothermic extracorporeal perfusion and leukocyte depletion for resuscitation of human donor kidneys. Perfusion 2010; 25: 343 .

104. Reznik O, Bagnenko S, Skvortsov A, et al. Rehabilitation of ischemically damaged human kidneys by normothermic extracorporal hemoperfusion in situ with oxygenation and leukocyte depletion. Transplant Proc 2010; 42: 1536

105. Reznik O, Skvortsov A, Loginov I, Ananyev A, Bagnenko S, Moysyuk Y. Kidney from uncontrolled donors after cardiac death with one hour warm ischemic time: resuscitation by extracorporal normothermic abdominal perfusion "in situ" by leukocytesfree oxygenated blood. Clin Transplant 2011; 25: 511.

106. Reznik ON, Skvortsov AE, Reznik $\mathrm{AO}$, et al. Uncontrolled donors with controlled reperfusion after sixty minutes of asystole: a novel reliable resource for kidney transplantation. PLoS One 2013; 8: e64209.

107. Rodríguez-Sanjuán JC, Ruiz N, Miñambres $\mathrm{E}$, et al. Liver transplant from controlled cardiac death donors using normothermic regional perfusion: comparison with liver transplants from brain dead donors. Transplant Proc 2019; 51: 12.

108. Rojas-Peña A, Sall LE, Gravel MT, et al. Donation after circulatory determination of death: the University of Michigan experience with extracorporeal support. Transplantation 2014; 98: 328.

109. Roncon-Albuquerque R, Gaião S, Figueiredo $\mathrm{P}$, et al. An integrated program of extracorporeal membrane oxygenation (ECMO) assisted cardiopulmonary resuscitation and uncontrolled donation after circulatory determination of death in refractory cardiac arrest. Resuscitation 2018; 133: 88.

110. Ruiz P, Gastaca M, Bustamante FJ, et al. Favorable outcomes after liver transplantation with normothermic regional perfusion from donors after circulatory death: a single-center experience. Transplantation 2019; 103: 938.

111. Sánchez-fructuoso AI, Prats D, Torrente $\mathrm{J}$, et al. Renal transplantation from non-heart beating donors: a promising alternative to enlarge the donor pool. J Am Soc Nephrol 2000; 11: 350 .

112. Savier E, Dondero F, Vibert E, et al. First experience of liver transplantation with type 2 donation after cardiac death in France. Liver Transpl 2015; 21: 631 .

113. Savier E, Lim C, Rayar M, et al. Favorable outcomes of liver transplantation from controlled circulatory death donors using normothermic regional perfusion compared to brain death donors. Transplantation 2020; 104: 1943.

114. Tchana-Sato V, Ledoux D, Detry O, et al. Successful clinical transplantation of hearts donated after circulatory death using normothermic regional perfusion. $J$ Heart Lung Transplant 2019; 38: 593.

115. Tchana-Sato V, Ledoux D, Vandendriessche $\mathrm{K}$, et al. First report of a successful pediatric heart transplantation from donation after circulatory death with distant procurement using normothermic regional perfusion and cold storage. J Heart Lung Transplant 2019; 38: 1112 .

116. Valdivia D, Gomez de Antonio D, Hoyos L, Campo-Canaveral de la Cruz JL, Romero A, Varela de Ugarte A. Expanding the horizons: Uncontrolled donors after circulatory death for lung transplantation-first comparison with brain death donors. Clin Transplant 2019; 33: e13561.

117. Valero R, Cabrer C, Oppenheimer F, et al. Normothermic recirculation reduces primary graft dysfunction of kidneys obtained from non-heartbeating donors. Transpl Int 2000; 13: 303.

118. Valero R, Manyalich M, Cabrer C, Salvador L, Garcia-Fages LC. Organ procurement from non-heart-beating donors by total body cooling. Transplant Proc 1993; 25: 3091.

119. Wang C-C, Wang S-H, Lin C-C, et al. Liver transplantation from an 
uncontrolled non-heart-beating donor maintained on extracorporeal membrane oxygenation. Transplant Proc 2005; 37: 4331.

120. Watson CJE, Hunt F, Messer S, et al. In situ normothermic perfusion of livers in controlled circulatory death donation may prevent ischemic cholangiopathy and improve graft survival. Am J Transplant 2019; 19: 1745.

121. Zambudio N, Fundora Y, Muffak K, et al. Experience of the transplant unit from Virgen de las Nieves hospital in using liver grafts from asystolic donors. Transplant Proc 2013; 45: 3573.

122. Zuckerman JM, Singh RP, Farney AC, Rogers J, Hines MH, Stratta RJ. Successful kidney transplantation from a donation after cardiac death donor with acute renal failure and bowel infarction using extracorporeal support. Transpl Int 2009; 22: 798.

123. Olthoff KM, Kulik L, Samstein B, et al. Validation of a current definition of early allograft dysfunction in liver transplant recipients and analysis of risk factors. Liver Transpl 2010; 16: 943.

124. Ito T, Botros M, Aziz A, et al. Nonanastomotic biliary strictures after liver transplantation. Am Surg 2020; 86: 1363.

125. Padilla M, Coll E, Fernández-Pérez C, et al. Improved short-term outcomes of kidney transplants in controlled donation after the circulatory deter- mination of death with the use of normothermic regional perfusion. Am J Transplant 2021. https://doi.org/10. 1111/ajt.16622 (epub ahead of print).

126. Vandendriessche K, Tchana-Sato V, Ledoux $\mathrm{D}$, et al. Transplantation of donor hearts after circulatory death using normothermic regional perfusion and cold storage preservation. Eur J Cardiothorac Surg 2021. https:// doi.org/10.1093/ejcts/ezab139 (epub ahead of print).

127. Manara A, Shemie SD, Large S, et al. Maintaining the permanence principle for death during in situ normothermic regional perfusion for donation after circulatory death organ recovery: a United Kingdom and Canadian proposal. Am J Transplant 2020; 20: 2017.

128. Mergental H, Laing RW, Kirkham AJ, et al. Transplantation of discarded livers following viability testing with normothermic machine perfusion. Nat Commun 2020; 11: 2939.

129. Nasralla D, Coussios CC, Mergental $\mathrm{H}$, et al. A randomized trial of normothermic preservation in liver transplantation. Nature 2018; 557: 50.

130. Jochmans I, Brat A, Davies L, et al. Oxygenated versus standard cold perfusion preservation in kidney transplantation (COMPARE): a randomised, doubleblind, paired, phase 3 trial. Lancet 2020; 396: 1653.
131. van Rijn R, Schurink IJ, de Vries Y, et al. Hypothermic machine perfusion in liver transplantation - a randomized trial. N Engl J Med 2021; 384: 1391.

132. Abt PL, Marsh CL, Dunn TB, et al. Challenges to research and innovation to optimize deceased donor organ quality and quantity. Am J Transplant 2013; 13: 1400.

133. Cooper J, Harvey D, Gardiner D. Examining consent for interventional research in potential deceased organ donors: a narrative review. Anaesthesia 2020; 75: 1229.

134. Boteon APCS, Schlegel A, Kalisvaart $\mathrm{M}$, et al. Retrieval practice or overall donor and recipient risk: what impacts on outcomes after donation after circulatory death liver transplantation in the United Kingdom? Liver Transpl 2019; 25: 545.

135. Ausania F, White SA, Coates R, Hulme W, Manas DM. Liver damage during organ donor procurement in donation after circulatory death compared with donation after brain death. Br J Surg 2013; 100: 381.

136. Krishnamoorthy V, McLean D, Ohnuma T, et al. Causal inference in perioperative medicine observational research: part 2, advanced methods. Br J Anaesth 2020; 125: 398. 